\title{
De aantrekkingskracht van bancassurance
}

Prof. Dr. R.A.H. van der Meer

\section{Inleiding}

Als verschijnsel is bancassurance niet nieuw. Ondernemingen in ver uit elkaar liggende landen als het Verenigd Koninkrijk, België en Canada zijn er al decennia nadrukkelijk mee bezig. Wat wel relatief nieuw is, is dat de belangstelling voor bancassurance in Europa de laatste tien jaren sterk gegroeid is. Bij belangstelling blifft het niet. Een groeiend aantal Europese banken en verzekeraars brengt bancassurance reeds in de praktijk. De wijze walarop geprobeerd wordt om van bancassurance een succes te maken, verschilt sterk van geval tot geval. Dat geldı ook voor het tot nu toe behaalde succes.

Als het succes van bancassurance niet verzekerd zou zijn, waarom dan toch geprobeerd"? In dit arlikel zal zowel in algemene zin als aan de hand van een praktijkvoorbeeld worden ingegaan op deze vraag. Eerst wordt het begrip bancassurance onder de loep gehouden, gevolgd door een korte schets van een aantal belangrijke ontwikkelingen die als achtergrond figureren voor de gegroeide aandacht voor bancassurance. Daarna worden algemeen geldende potentiële voordelen en belemmeringen van bancassurance besproken. Aan de hand van Fortis, het langstbestaande bancassurance-concern in België en Nederland, wordt vervolgens geillustreerd op welke wijze bancassurance succesvol geïmplementeerd kan worden. Zo zijn ASLK in België en CAIFOR in

Prof. Dr. R.A.H. van der Meer is lid van de Raad van Bestuur van Fortis AMEV. Tevens is hij deeltijd hoogleraar in de Bedrijfseconomie, in het bijzonder beleggingsleer en vermogensbeheer, aan de Rijksuniversiteit Groningen.
Spanje beide nu marktleider bij levensverzekeringen. Een samenvatting rondt het betoog af.

\section{Het begrip bancassurance}

Over wat bancassurance inhoudt bestaat enige verwarring. Het begrip bancassurance wordt veelal vaag dan wel als specifiek op één situatie van toepassing zijnde, omschreven. Een universeel gehanteerde definitie bestaat niet. Vrij algemeen wordt gesproken over alleen consumenten als relevante afnemers, hoewel bancassurance ook van toepassing kan zijn op zakelijke afnemers. Gemakshalve wordt in dit artikel bij dit gebruik aangesloten. Soms wordt bancassurance gelijkgesteld aan het aanbieden van verzekeringsprodukten via bancaire distributiekanalen, al dan niet op exclusieve basis. Ook wordt wel over bancassurance gesproken wanneer vanuit één concern alle voorkomende bancaire en verzekeringsdiensten (separaat) worden aangeboden. Afhankelijk van de situatie wordt ook de term 'assurbanking' gehanteerd, in principe hetzelfde begrip, maar met de nadruk op de distributie van bancaire produkten door het assurantie-intermediair.

Een andere voorkomende benaming is Allfinanz, wellicht het best te omschrijven als het aanbieden van alle mogelijke financiële produkten en diensten via alle mogelijke distributiekanalen aan alle mogelijke klanten. In dit artikel zal consequent het woord bancassurance worden gehanteerd en wordt het als volgt omschreven:

Bancassurance is de combinatie van bancaire en verzekeringsactiviteiten op één of meer aspecten, waardoor loegeroegde waarde wordt gecreëerd. 
Zoals hierna duidelijk wordt gemaakt, is er een logische ontwikkeling te zien die toont dat deze waardecreatie het best gerealiseerd kan worden indien de bancaire- en verzekeringsactiviteiten binnen één concern zijn gebundeld. Dit sluit andere manieren niet uit. Het verkopen van verzekeringsprodukten via bankkanalen of bankprodukten via verzekeringskanalen is mogelijk zonder dat producent en distributeur samengaan in één concern. Er zijn evenwel potentiële belemmeringen die in zo'n situatie het creëren van waarde bemoeilijken. Een fusie of acquisitie is dan ook een wenselijke eerste stap gebleken om bancassurance ten volle te kunnen realiseren.

\section{Relevante ontwikkelingen}

De recente, sterke opkomst van bancassurance in West-Europa kan niet los worden gezien van andere ontwikkelingen die zich op uiteenlopende gebieden hebben voorgedaan. Bancassurance kan zelfs nóg minder los worden gezien van ontwikkelingen zoals die zich naar verwachting in de toekomst zullen gaan voordoen.

\section{I Vraag en aanbod}

In de na-oorlogse jaren, toen de aandacht uitging naar herstel van de geleden schade en de creatie van nieuwe welvaart, was tot in de jaren ' 60 sprake van een sterk groeiende vraag naar financiële produkten. Zowel op bancair vlak als op verzekeringsgebied richtte de aandacht van aanbieders zich vooral op het kunnen voldoen aan die ongedifferentieerde vraag. Daarna begon een periode waarin differentiatie van produkten en distributie belangrijker werd om de afzetgroei te kunnen continueren. Ondernemingen richtten zich op grotere of kleinere segmenten van de markt. Door fusies werden klantenbestand en produktenaanbod uitgebreid. Vervolgens kondigde zich in de tweede helft van de tachtiger jaren een volgende fase aan: bancassurance. In de in toenemende mate verzadigde markten vormen de behoef-

Tabel 1: Ontwikkelingen bij aanbieders 1960-1990

\begin{tabular}{|c|c|}
\hline Marketing & Aanbieders \\
\hline Mass-marketing & Gespecialiseerde bank of verzekeraar \\
\hline $\begin{array}{c}\text { Produkt-marketing } \\
1\end{array}$ & $\begin{array}{c}\text { Retailbank of verzekeringsconcern } \\
\text { | }\end{array}$ \\
\hline Cliënt-marketing & Bancassurance-instelling \\
\hline
\end{tabular}

ten van de klant het vertrekpunt voor doen en laten van de aanbieders. Optimaal gebruik van fiscale faciliteiten staat hoog op de verlanglijst van de klant. Waarbij 'de' klant theoretisch gezien een individuele klant is, hoewel in de praktijk daarnaast ook sprake kan zijn van kleine groepen met overeenkomende behoeften.

De ontwikkelingen aan de vraagkant vinden hun spiegelbeeld aan de aanbodzijde. Tabel 1 schetst deze ontwikkeling. Van massaproducent van alleen bancaire of verzekeringsprodukten via aanbieder van een breed scala van financiële produkten en diensten, grotendeels nog uit de eigen bedrijfstak, zijn de aanbieders nu bancassurance-instellingen geworden. Door het binnen één bancassurance-concept integreren van eigenschappen van wat voorheen twee verschillende produktcategorieën waren, bancaire en verzekeringsprodukten, vervaagt het onderscheid tussen beide categorieën in snel tempo.

\subsection{Informatietechnologie}

De explosieve ontwikkelingen op het terrein van informatietechnologie (IT) hebben hierbij een niet te onderschatten rol gespeeld. Naarmate de complexiteit van financiële produkten en diensten (gemakshalve wordt in dit artikel steeds de term 'produkten' gehanteerd) toeneemt, stijgen ook de administratieve eisen. IT maakt het mogelijk aan die eisen te blijven voldoen.

Daarnaast lijken technologische ontwikkelingen zoals Internet een eigen impuls te geven aan nieuwe ontwikkelingen. Naast administratieve toepassingen worden met name distributieve toepassingen steeds actueler. Zo brengt Internet de virtuele bank binnen bereik. In de Verenigde Staten opereert Security First Network Bank sinds kort als eerste virtuele bank, zonder gebruikmaking van kantoren of derde partijen als distributiekanaal. Ook verzekeraars oriënteren zich op de mogelijkheden van nieuwe technologieën voor distributie en back-office. Al deze IT ontwikkelingen zullen uiteraard de mogelijkheden en voordelen van bancassurance verder blijven vergroten.

\subsection{Demografische trends}

De eerder geschetste wens om middels bancassurance op het behoeftepatroon van een klant in te spelen, verklaart mede de belangstelling voor het 'consumer life-cycle' denken. De behoeften van 
de klant op financieel terrein veranderen voortdurend tijdens zijn leven. Lenen of sparen, risico dragen of mijden, opbouwen van vermogen of het opeten ervan, elke consument heeft hiermee te maken. Maar niet altijd in dezelfde levensfase.

Bancassurance-instellingen zijn in staat om hier pro-actief op in te spelen door creatieve produktontwikkeling, opdat de klant in iedere levensfase optimaal wordt bediend.

Naast bancaire en verzekeringseigenschappen, zullen bancassurance-produkten ook nadrukkelijk beleggingskenmerken in zich gaan bergen. Naarmate een klant ouder wordt worden de beleggingsaspecten van bancassurance-produkten belangrijker voor hem. De geconstateerde demografische trends naar een stijgende gemiddelde leeftijd van de bevolking in de meeste landen van de Europese Unie - en vele daarbuiten -, meestal kort aangeduid met het woord 'vergrijzing', geeft hiermee een extra dimensie aan het bancassurance-concept (zie tabel 2).

Tabel 2: Demografische trends: aantal 65-plussers als percentage van het aantal 15-64 jarigen

\begin{tabular}{llll}
\hline & 1990 & 2010 & 2030 \\
\hline Duitsland (West) & 22,5 & 30,3 & 43,4 \\
Frankrijk & 21,0 & 24,0 & 35,9 \\
Nederland & 18,5 & 21,8 & 38,0 \\
België & 21,1 & 23,1 & 35,0 \\
Spanje & 19,3 & 23,0 & 32,1 \\
Zwitserland & 25,0 & 40,0 & 50,1 \\
\hline
\end{tabular}

(2010 en 2030 : verwachtingen)

\subsection{Pensioen}

Deze laatste stelling wordt onderstreept door de in veel Europese landen bestaande situatie op pensioengebied, waar nationale oudedagsvoorzieningen zijn gebaseerd op het zogenaamde 'pay-asyou-go' systeem. Het actieve bevolkingsdeel betaalt de oudedagsvoorziening voor het nietmeer-actieve deel. De komende vergrijzing maakt dit systeem op termijn onhoudbaar, een situatie waarvan overheden èn consumenten zich steeds nadrukkelijker bewust worden. Hierdoor zal de vraag naar additioneel inkomen-genererende produkten met beleggingskenmerken gedurende een lange periode autonoom stijgen. Het voert te ver in het kader van dit artikel om op deze problematiek dieper in te gaan. Ter illustratie van de omvang van de mogelijkheden die dit biedt, zij nog vermeld, dat in de Verenigde Staten met zijn beperkte overheidssysteem van oudedagsvoorziening, circa $\$ 3,8$ biljoen middels een kapitaalsdekkingstelsel belegd is ten behoeve van pensioenuitkeringen. In de landen van de Europese Unie met hun veel grotere bevolking, 440 miljoen versus 260 miljoen mensen, is dit slechts $\$ 1,6$ biljoen (M. Hurley, Goldman, Sachs \& Co, 1995).

De consument wordt ook minder solidair en verlangt steeds meer maatwerk: de pensioenbehoefte wordt geïndividualiseerd. Het pensioen wordt door de klant ingepast in zijn totale behoefte aan maatwerk op financieel gebied. Pensioenfondsen zullen hieraan tegemoet willen komen. De hieruit resulterende flexibilisering of 'opsplitsing' in onderdelen van het pensioenprodukt, maakt dat die onderdelen ook beschikbaar zullen komen voor integratie of afstemming met een bancassuranceprodukt. Ook pensioenfondsen kunnen dus een rol gaan spelen bij het verschijnsel bancassurance.

\section{Voordelen van bancassurance}

Met de in het voorgaande hoofdstuk beschreven ontwikkelingen als achtergrond kan de aantrekkelijkheid van het bancassurance-concept worden toegelicht. Om te zien op welke aspecten bancaire en verzekeringsactiviteiten gecombineerd kunnen worden, is in tabel 3 in een viertal kolommen aangegeven welke toegevoegde waarde kan worden gecreëerd. Hiermee is tegelijkertijd een groot aantal voordelen genoemd die behaald kunnen worden door het samengaan van bank en verzekeraar in één onderneming. Dit samengaan zal uiteindelijk kunnen veranderen in 'in elkaar opgaan'. Tabel 3 is gebaseerd op de waardeketen van Porter (M. Porter, 1985) en geeft de waardeketen weer voor een bancassurance-concern.

Het is niet uitgesloten dat in voorkomende gevallen meer voordelen aan deze opsomming kunnen worden toegevoegd, maar de voornaamste zijn in tabel 3 verwerkt. Terzijde zij opgemerkt dat sommige voordelen ook behaald kunnen worden indien twee banken of twee verzekeraars samengaan. Naast het voordeel van aanvullende activiteiten betreft dit vooral schaalvoordelen. Op die situatie wordt verder niet ingegaan. 
Tabel 3: Voordelen bancassurance

\begin{tabular}{|c|c|c|c|}
\hline $\begin{array}{l}\text { Produktontwerp, } \\
\text { prijsstelling }\end{array}$ & $\begin{array}{l}\text { Klantbenadering, } \\
\text { distributie }\end{array}$ & $\begin{array}{l}\text { Administratie, claim- } \\
\text { afhandeling, systemen }\end{array}$ & $\begin{array}{l}\text { Beleggingsbeleid. } \\
\text { funding }\end{array}$ \\
\hline $\begin{array}{l}\text { Gezamenlijke } \\
\text { ontwikkeling van } \\
\text { levenprodukten } \\
\text { voor bankkanaal } \\
\text { en intermediairkanaal }\end{array}$ & $\begin{array}{l}\text { Verbeterde cross- } \\
\text { selling door het } \\
\text { kunnen invullen van } \\
\text { one-stop-shopping } \\
\text { concept }\end{array}$ & $\begin{array}{l}\text { Toegang tot systeem- } \\
\text { expertise en ontwikkel- } \\
\text { capaciteit }\end{array}$ & $\begin{array}{l}\text { Schaalvoordelen bij } \\
\text { trust en asset mgmt. } \\
\text { Verbetering van } \\
\text { rendement/risico }\end{array}$ \\
\hline $\begin{array}{l}\text { Gezamenlijke } \\
\text { ontwikkeling } \\
\text { schadeprodukten } \\
\text { voor bankkanaal } \\
\text { en intermediairkanaal }\end{array}$ & $\begin{array}{l}\text { Verkoop van gestan- } \\
\text { daardiseerde pull- } \\
\text { produkten via goedkoper } \\
\text { bankkantorennetwerk } \\
\text { en bankformule inter- } \\
\text { mediair }\end{array}$ & $\begin{array}{l}\text { Schaalvoordelen in } \\
\text { back-office en systemen } \\
\text { Besparingen op overhead } \\
\text { Beheersing additionele } \\
\text { geldstromen, inkoop e.d }\end{array}$ & $\begin{array}{l}\text { Performance door } \\
\text { bundeling van de } \\
\text { beleggings- } \\
\text { deskundigheid van } \\
\text { verzekeraar en bank }\end{array}$ \\
\hline $\begin{array}{l}\text { Betere vaardigheden } \\
\text { m.b.t. prijsstelling } \\
\text { Gemakkelijker ont- }\end{array}$ & $\begin{array}{l}\text { Starten 'dedicated sales } \\
\text { force' ondersteund door } \\
\text { 'warm leads' van bank: } \\
\text { financial planning bank }\end{array}$ & & $\begin{array}{l}\text { Optimalisering van } \\
\text { balansstructuur } \\
\text { (ALM) }\end{array}$ \\
\hline $\begin{array}{l}\text { toegesneden op ver- } \\
\text { schillende marktseg- } \\
\text { menten als basis } \\
\text { voor multi-channel } \\
\text { aanpak }\end{array}$ & $\begin{array}{l}\text { Toegang tot expertise } \\
\text { van verzekeraar op het } \\
\text { gebied van management } \\
\text { van eigen buitendienst } \\
\text { Aanbieden verschillende } \\
\text { prijs/kwaliteit-combinaties } \\
\text { aan verschillende markt- } \\
\text { segmenten }\end{array}$ & & $\begin{array}{l}\text { Betere toegang } \\
\text { kapitaalmarkt }\end{array}$ \\
\hline
\end{tabular}

Zowel bank als verzekeraar beschikken over omvangrijke databases met daarin opgenomen allerhande gegevens van hun klanten. Met name zal een bank, die vaak met haar klanten een totaalrelatie heeft, een schat aan informatie hebben. Analyse daarvan kan klantenbehoeften zichtbaar maken waaraan door de combinatie van bank en verzekeraar, nog beter kan worden worden voldaan. Een coherente marketingbenadering wordt mogelijk.

In eerste instantie zal cross-selling succesvol kunnen zijn. In een volgende fase zal het verworven inzicht moeten leiden tot nieuwe produkten en diensten met een bancassurance-karakter, die optimaal voorzien in de behoeften van de klant gedurende diens gehele levenscyclus. Tegen de achtergrond van de in hoofdstuk 2 geschetste ontwikkelingen ziet bijvoorbeeld een bankverze- keraar als Fortis daarom ook beleggen als een sterk in belang groeiende volwaardige, commerciële activiteit, naast het bankieren en verzekeren.

\section{Mogelijke belemmeringen om bancassurance te realiseren}

Alvorens in te gaan op een praktijkvoorbeeld, is het zinvol om stil te staan, in algemene zin, bij de belemmeringen die actueel kunnen zijn of worden bij het samengaan van bancaire en verzekeringsactiviteiten in één bancassurance-onderneming. De belemmeringen beïnvloeden niet het principe van bancassurance, maar treden op als stoorzender en vertragende factor bij de operationalisering ervan.

Kortheidshalve wordt over de meest voorkomende situatie gesproken, namelijk die van een 
samengaan van bank en verzekeraar. Het de novo beginnen van bankactiviteiten door een verzekeraar of vice versa, zal de in de tweede kolom van tabel 4 vermelde belemmeringen ook ondervinden maar deels in geringere mate, vanwege het "erin groeien'.

Belemmeringen kunnen worden onderverdeeld in belemmeringen die zich in principe altijd kunnen voordoen wanneer twee ondernemingen samengaan èn in belemmeringen die alleen een rol spelen, dan wel die zich juist in versterkte mate kunnen voordoen, wanneer twee ondernemingen samengaan die afkomstig zijn uit wat voorheen als twee bedrijfstakken werd gezien.

De scheidslijn tussen deze twee categorieën is uiteraard niet haarscherp te trekken. Het mag duidelijk zijn dat op een bancassurance-onderneming die ontstaan is uit het samengaan van twee verschillende ondernemingen, beide categorieën van toepassing zijn. In dit artikel wordt slechts op de tweede categorie nader ingegaan.

Tabel 4: Mogelijke belemmeringen bij bereiken bancassurance

\begin{tabular}{ll}
\hline Algemeen & Bancassurance \\
\hline Coördinatiekosten & Verschillende toezicht- \\
Compromiskosten & houdende instanties \\
Inflexibiliteitskosten & Produkt-typische \\
Bedrijfs-cultuurverschillen & kenmerken \\
IT-verschillen & Grootteverschillen \\
& partners \\
& Bedrijfstakverschillen \\
& Klantgedrag \\
\hline
\end{tabular}

4.1 Verschillende toezichthoudende instanties: De Nederlandsche Bank en de Verzekeringskamer

Het bestaan van twee toezichthoudende instanties heeft het samengaan van banken en verzekeraars niet onmogelijk gemaakt, zoals de praktijk bewijst. Het blijft evenwel een belemmerende factor in die zin dat voor beide instanties een aparte rapportagestroom onderhouden moet worden. Dil zal naarmate de operationele integratie van diensten en produkten, en bedrijfsonderdelen, verder voortschrijdt - een onherroepelijk proces - steeds meer gevolgen hebben met betrekking tot verdeling van opbrengsten en kosten. Het gescheiden moeten rapporteren kan een belemmering vormen voor de procesinrichting.

\subsection{Produkt-typische kenmerken}

Diensten en produkten van bank en verzekeraar hebben ieder hun kenmerken. Vormt dit aan de ene kant de aantrekkelijkheid van het combineren ervan in een nieuw bancassurance produkt, aan de andere kant neemt hierdoor de complexiteit sterk toe.

Dit geldt vooral op IT-gebied, nog versterkt door een zich voortdurend wijzigende fiscale regelgeving. De noodzakelijke ontwikkelingstijd en -kosten vormen in sommige situaties een belemmering voor een snelle implementatie. Ze beïnvloeden tevens de prioriteitenstelling.

\subsection{Bedriffstakerschillen}

In combinatie met verschillen in bedrijfscultuur (de grens is moeilijk te trekken) vormen de verschillen tussen bedrijfstakken wellicht de meest belemmerende factor binnen een bancassuranceonderneming. Verplichtingen van verzekeraars aan hun klanten hebben veelal een zeer lange tijdshorizon die meteen op het moment van verkoop begint. Dat geldt zowel voor levensverzekeringen (pensioen) als voor schadeverzekeringen (aansprakelijkheid). Ook banken kennen langlopende verplichtingen en vorderingen, zoals spaargelden en hypotheken. In de praktijk blijkt dat verzekeraars nadrukkelijker dat lange termijnkarakter van hun werkzaamheden in hun doen en denken meenemen dan bankiers. Er is sprake van een verschillende risicoperceptie. Deze verschillende achtergronden spelen een rol bij het integratieproces van bank- en verzekeringsprodukten in één bancassurance-produkt.

Daarnaast verzorgt een bank traditioneel zowel produktie als distributie van haar diensten en produkten geheel in eigen beheer. Een verzekeraar die gebruik maakt van het intermediairkanaal is voor distributie afhankelijk van derden. Hij is immers geen 'eigenaar' van zijn klanten. Een bancassurance-onderneming zal op evenwichtige wijze gebruik moeten maken van de haar ter beschikking staande distributiekanalen opdat de markt zo goed mogelijk kan worden bediend. Datzelfde geldt voor produkteigenschappen. Verder moeten het verkoopsysteem van produktie-afhankelijke beloning van een 
verzekeraar, gericht op het vrije intermediair, en het salariëringssysteem van een bank op elkaar worden afgestemd, om te voorkomen dat ongewenste (qua aard of snelheid) substitutie plaatsvindt tussen bancaire en verzekeringsprodukten.

\subsection{Grootteverschil bank en verzekeraar}

Dit verschil zal eerder voor de praktische uitwerking dan voor het principe van bancassurance een potentiële belemmering vormen. De combinatie van een grote bank met een kleinere 'dedicated' verzekeraar zal waarschijnlijk het snelst tot resultaten leiden. Met name de administratieve afstemming of integratie verloopt vlotter. De kans bestaat evenwel dat vanwege het risico op kannibalisme met traditionele bankprodukten, bancassurance toch niet kan floreren en dat de verzekeringsactiviteiten in de praktijk slechts als aanvulling zullen dienen op het hoofdbedrijf, de bank. Mutatis mutandis geldt hetzelfde voor een grote verzekeraar en een kleine bank. Bij een minder pregnant verschil in omvang zal aan beide meer recht worden gedaan. De verhouding tussen de grootte van bank en verzekeraar bepaalt dus mede de resulterende invalshoek ten aanzien van bancassurance.

\subsection{Klantgedrag}

Het onder één dak kunnen aanbieden van het gehele scala van financiële diensten is een groot voordeel voor veel klanten. Een klant heeft dan de zekerheid dat op grond van zijn persoonlijke situatie, een optimale, geïndividualiseerde afstemming kan plaatsvinden van financiële produkten en diensten. Zo heeft Fortis Nederland een frontoffice adviesmodel ontwikkeld waarin onder andere de fiscale regels worden gekoppeld aan wensen en mogelijkheden van de klant. Hierdoor kan een totaal-advies worden gegeven waarin bancaire en verzekeringsaspecten integraal worden meegenomen.

Een potentieel mogelijk nadeel in de ogen van de klant is evenwel dat hiermee een ongewenst afhankelijkheid(sgevoel) kan ontstaan. Een bancassurance-onderneming die onbewust en ongewild dit gevoel zou creëren, bijvoorbeeld door te snel en te intensief data base mining te gaan implementeren, loopt hiermee dus een zeker afbreukrisico. De klant kan reageren door relaties met meer instellingen aan te gaan en tot een produktenafnemer te worden.

\section{Bancassurance in praktijk}

Bancassurance ontwikkelt zich wereldwijd maar heeft vooral in Europa een grote vlucht genomen. Wat daarbij opvalt is de grote verscheidenheid in benaderingswijze van de betreffende ondernemingen (zie T. Hoschka, 1994), gedicteerd door een even groot verschil in uitgangspositie en omstandigheden. Niet alle benaderingswijzen zijn even succesvol. Met name bij allianties tussen distributeur en producent kan een ongelijke betrokkenheid van de partners het succes in de weg staan. Het volledig samengaan van bank en verzekeraar kan het vrijblijvende karakter dat allianties kunnen hebben, voorkomen. Bovendien kunnen de fusiepartners niet enkele, maar alle voordelen van bancassurance realiseren inclusief die in de back-office.

\section{5.l Europese voorbeelden}

In Groot-Brittannië werd bancassurance gestimuleerd door de Financial Services Act van 1986. Deze wet is erop gericht de distributie en verkoop van beleggings- en levensverzekeringsprodukten te reguleren. In deze wet wordt er een strikt onderscheid gemaakt tussen enerzijds onafhankelijke tussenpersonen en anderzijds gebonden tussenpersonen. De Financial Services Act stimuleerde niet alleen de ontwikkeling van eigen distributienetwerken door verzekeraars, ook de banken ontwikkelden hun verkoopapparaat voor distributie van verzekeringsprodukten van verzekeraars. Enkele banken ruilden de positie van onafhankelijk tussenpersoon in voor een duidelijke financiële relatie met één verzekeraar. Zo heeft Lloyds Bank in 1988 de verzekeringsactiviteiten ondergebracht bij Abbey Life, een grote beursgenoteerde levensverzekeraar in ruil voor 58 procent van de aandelen Abbey Life. De recente fusie met geïntegreerde bankverzekeraar TSB kan overigens Lloyds Bank aan haar bancassurance strategie mogelijk een nieuwe invulling doen geven. National Westminster Bank heeft sinds 1991 een samenwerkingsverband met Clerical Medical, één van de grote onderlinge levensverzekeringsmaatschappijen. Ook hebben er zich samenwerkingsverbanden ontwikkeld met bouwfondsen, zoals Friends' Provident met het grootste 
bouwfonds Abbey National. die in 1987 een gezamenlijke marketing-overeenkomst sloten.

In Frankrijk worden al sinds enkele jaren relatief eenvoudige op levensverzekeringen gebaseerde spaarprodukten verkocht. Om het potentieel te ontwikkelen voor relatief meer complexe produkten is een aantal samenwerkingsverbanden ontstaan, zoals dat tussen Banque Nationale de Paris (BNP) en Union des Assurances de Paris (UAP), verstevigd door kruiselingse aandelenbelangen.

Eerstgenoemde verkoopt schadeprodukten van deze verzekeraar. terwijl UAP hypotheken en persoonlijke leningen van de bank promoot.

Ook in Duitsland. Spanje en Italië ziet men samenwerkingsverbanden, alsmede in Nederland, zoals de samenwerking tussen Nationale-Nederlanden en NMB Postbank onder ING. Voor andere Europese voorbeelden wordt verwezen naar $T$. Hoschka.

In 1990 was reeds de samenwerking aangekondigd tussen de Verenigde Spaarbank (nu VSB geheten) en verzekeraar NV AMEV. Hiermee maakten zij als eerste gebruik van de opheffing van de scheiding tussen banken en verzekeraars en introduceerden aldus bancassurance in Nederland.

\subsection{Praktijkioorbeeld Fortis}

Middels Europese Richtlijnen werd en wordt gewerkt aan het creëren van één grote Europese markt voor financiële diensten. De eenwording binnen de Europese Unie bleek een stimulans te zijn om grenzen te slechten: het samengaan van VSB en NV AMEV werd kort daarop gevolgd door het samengaan met de Belgische verzekeraar Groupe AG. Zo ontstond een krachtige internationale financiële groep genaamd Fortis. De twee moedermaatschappijen Fortis AMEV en Fortis $A G$ zijn aan de beurs genoteerd en houden ieder 50 procent van Fortis (zie figuur 1).

Figutur 1: Fortis organigram

\begin{tabular}{|c|c|c|}
\hline \multicolumn{2}{|c|}{ FORTIS AMEV } & \multicolumn{2}{|c|}{ FORTIS AG } \\
\hline $50 \%$ & $50 \%$ \\
\hline \multicolumn{2}{|c|}{ F O R T I S } \\
\hline
\end{tabular}

Bancassurance is één van de hoofddoelstellingen van Fortis. Op bancair, verzekerings- en beleggingsgebied is Fortis inmiddels uitstekend gepositioneerd om van bancassurance een succes te maken, ook internationaal. Op de recent gepubliceerde Fortune 500-lijst stond Fortis op de 146e plaats.

Hier is zorgvuldig naar toe gewerkt. Een duidelijke sprong voorwaarts werd gemaakt in 1993 toen een belang werd verworven in de grote Belgische spaarbank ASLK. ASLK is al sinds de vorige eeuw actief in de verkoop en produktie van verzekeringen. Bankbedrijf en verzekeringsbedrijf zijn vanaf het begin in 1865 gezamenlijk uitgeoefend, waarmee ASLK één van de allereerste Europese bancassurance-instellingen werd ofschoon gezien de ontstaansgeschiedenis ook van assurbanking kan worden gesproken. ASLK benut de mogelijkheden van bancassurance ten volle. Zo worden bijvoorbeeld in de bankkantoren individuele levensverzekeringspolissen on-line opgemalakt en afgegeven. Dit verklaart mede het marktleiderschap en de bovengemiddelde groei op dit terrein van ASLK.

In 1992 is een samenwerking tot stand gekomen tussen Fortis en 'la Caixa'. de grootste Spaanse spaarbank. Met de bankkantoren van 'la Caixa' als distributiekanaal bezette de joint venture CAIFOR qua premie-inkomen in 1994 de eerste plaats in de levensverzekeringenmarkt. Dat in Spanje in korte tijd veel van de in tabel 3 genoemde voordelen van bancassurance gerealiseerd konden worden, illustreert het potentieel van het concept.

\section{Samenvatting}

Bancassurance kan worden omschreven als de combinatie van bancaire- en verzekeringsactiviteiten op één of meer aspecten. waardoor waarde wordt toegevoegd.

Het toevoegen van waarde gebeurt op de terreinen van produktontwerp en prijsstelling, van klantbenadering en distributie, van administratie, claimathandeling en systemen, alsmede het terrein van beleggingsbeleid en funding. Velerlei voordelen kunnen hier behaald worden in de sfeer van zowel lagere gemiddelde kosten, als van betere produkten en dienstverlening aan de klanten. Belemmeringen voor het bancassurance-concept zijn van praktische aard en zijn in 
principe overkoombaar. Het zorgvuldig met de belemmeringen omgaan is hiervoor een voorwaarde. De brede omarming van het bancassurance-concept door beide bedrijfstakken bewijst dat de verwachte toegevoegde waarde hoger is dan de geanticipeerde additionele kosten. De aantrekkelijkheid van het concept staat buiten kijf. Maar het succes van bancassurance is niet verzekerd. Een duidelijke strategie en zorgvuldige uitvoering zijn vereist om alle voordelen ervan te kunnen plukken.

Vanaf haar ontstaan heeft Fortis bancassurance als hoofddoelstelling gehad. In België is hieraan uitvoering gegeven door toetreding van ASLK, die al jarenlange ervaring op dit terrein heeft. Ook het succes van CAIFOR in Spanje onderstreept de mogelijkheden van het bancassurance-concept. Conform 'structure follows strategy' is de organisatie van Fortis in Nederland inmiddels fundamenteel aangepast. Belemmeringen die het behalen van alle potentiële voordelen van bancassurance bemoeilijkten, worden zo weggenomen of minstens gereduceerd. Hierdoor kan bancassurance in al haar aspecten nog beter en sneller worden gerealiseerd.
Door het gericht ten uitvoering brengen van de uitgestippelde strategie bepaalt Fortis zelf de aantrekkelijkheid van bancassurance. En plukt later de vruchten.

\section{I T E R A T U U R}

Brown, B., (1992), Allfinanz without limits, Lafferty Publications, Ltd., Dublin.

CBS.

Coopers \& Lybrand, (1993), Making bancassurance work, Amsterdam.

Hoschka, Tobias C., (1994), Bancassurance in Europe, The Macmillan Press Ltd., Great Britain.

Hurley, M.P. et al, (1995), The Coming Evolution of the Investment Industry, Goldman Sachs.

Leach, A., European Bancassurance, Problems and Prospects to 2000, FTBE Ltd., London.

Mitra, R., (1995), European Pensions.

OECD.

Petersen, C., (1995), Vernieuwing en samenwerking op de vermogensmarkt, ESB.

Porter, M.E., (1985), Competitive Advantage, The Free Press, New York. 